\title{
Da doença das virgens: tradução e comentários
}

\author{
Julieta Alsina \\ Mestrado - UFRJ
}

Orientador: Prof. Doutor Henrique Fortuna Cairus

\section{Apresentação}

O tratado hipocrático Пepì ra $\beta \theta \varepsilon v i ́ \omega v$ é um opúsculo que trata da descrição e da etiologia de uma doença em particular, que afeta as jovens virgens que chegam à idade do casamento e não se casam. Escrito no IV século, segundo a datação proposta por Jacques Jouanna (1992:548), o tratado se insere no grupo dos tratados ginecológicos, junto aos Da natureza da mulher, Das doenças da mulheres, Das mulheres estéreis, entre outros, todos aliás pertencentes à escola de Cnido (García Gual, 1988). Jacques Jouanna, no entanto, acredita que o tratado seja um fragmento de um maior dedicado às doenças em geral, sem aparente relação com aqueles, motivado a tal hipótese, em parte, pelo conteúdo do prólogo:

O princípio da composição da medicina é o mesmo das coisas eternas: não se pode conhecer a

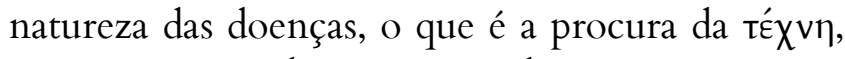
se não se a conhece através do seu princípio, a partir do qual a julga ${ }^{1}$

O tratado médico Da doença das virgens descreve como as jovens virgens

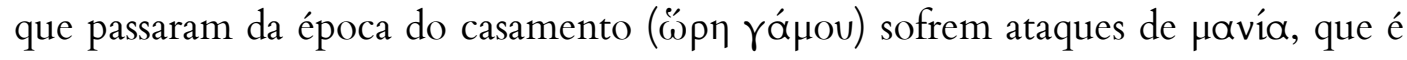
descrita no tratado tal qual a histeria pré-charcotiana. O médico atribui tal $\mu$ «vía à

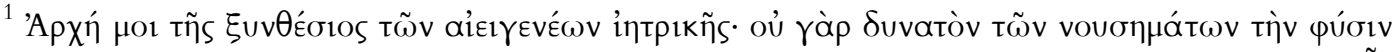

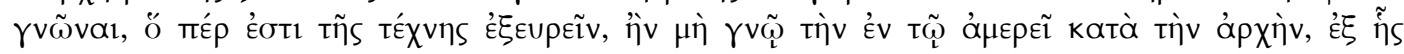

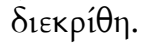


ação fisiológica da virgindade, ou do não rompimento do hímen quando passada a idade do casamento, ou seja, logo após a menarca - associando essa condição à 'doença sagrada', comumente identificada com a epilepsia ${ }^{3}$, que, segundo ele, afeta mais mulheres do que homens, uma vez que "a natureza feminina é menos forte e sem Өupós”. Assim, o acúmulo de sangue no útero, devido à falta de abertura do canal de saída - provocada pelo inconveniente integridade do hímen - faz com que o sangue extravase e suba em direção ao coração e ao diafragma, provocando palpitações e também intumescimento dos membros, o que desencadeia um estado

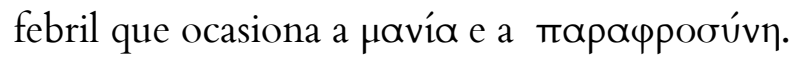

Segundo o breve tratado, sob o efeito desses sintomas, algumas mulheres recorrem a oráculos e a curandeiros e são persuadidas a fazer oferendas a Ártemis, deusa tradicionalmente associada ao processo de amadurecimento e às doenças das mulheres (King, 2004, p.48). Mas diferente do Da doença sagrada, o nosso autor não ataca nem condena tais práticas; ao contrário, ele descreve seus métodos e, a partir do seu lugar de médico, oferece o seu diagnóstico e prescrição.

A observação e descrição desses sintomas nos oferecem, a primeira vista, um texto meramente técnico e descritivo. O tom moral, obnubilado pela pretensa isenção em todo o texto do tratado, revela-se no último parágrafo, onde se lê:

Ordeno, por minha parte, às virgens que padecem tal mal, a se casarem o mais rápido possível com homens; pois, se engravidam, tornam-se sãs. Se não, durante a adolescência ou pouco depois, serão tomadas por esta ou por outra doença. Dentre as mulheres casadas, as estéreis padecem estes males. ${ }^{4}$

\footnotetext{
${ }^{2}$ Não há, no entanto, no tratado, qualquer referência ou relação ao tratado homônimo. (García Gual, 1988 , p.327 infra)

${ }^{3}$ ver Cairus, 1999.

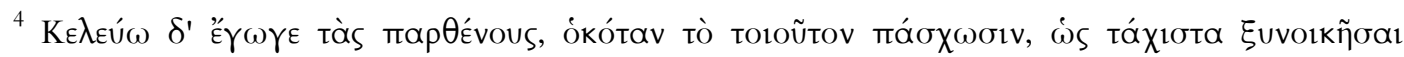

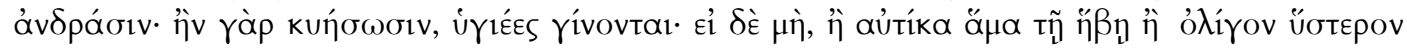

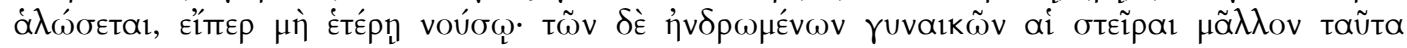

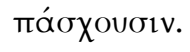


Assim, o pequeno tratado propõe uma relação entre a virgindade, a idade e a $\mu \alpha$ vía. A partir dessa relação não é difícil acompanhar um processo de construção argumentativa, em que o autor parece entrelaçar dois valores: um, relativo à doença e à sua etiologia, e outro, relativo a um 'saber comum' social, o que, segundo Pinault (apud King, 2004, p.48), pode ser visto como um 'instrumento de socialização. Por sua natureza, o tratado nega o quanto possível relações com princípios valorativos, para pensar a virgindade a partir de sua relação com a saúde e a doença.

O texto de que aqui tratamos faz parte de um mosaico discursivo que depõe acerca do significante 'virgindade' e das práticas e valores que o tecem. Na cultura grega, mesmo considerando-a em unidade, a virgindade comporta significados desde tempos imemoriais, de onde se pensa provir o mito do Minotauro que devorava virgens. Não se pode, de resto, considerar casual que a lenda do Minotauro ocupe um lugar de mito fundador da cidade de Atenas.

Entre esses discursos que tangem a virgindade e o casamento, ressalta-se em especial aqueles que a tematizam. Um exemplo dessa ordem são os himeneus de Safo de Lesbos, em que facilmente é possível entrever o valor atribuído à virgindade e a sua estreita relação com o ritual do casamento:

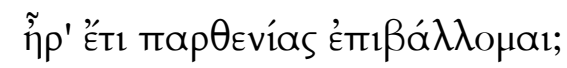

$$
\begin{aligned}
& \text { Desejarei ainda a virgindade? (fr. 107L-P) }
\end{aligned}
$$

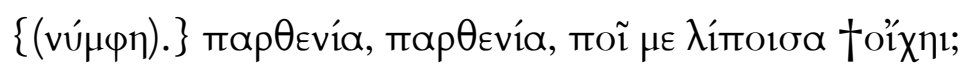

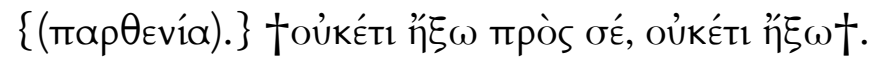

$\{($ noiva $)\}$ virgindade, virgindade, para onde foste, que me abandonaste?

$\{($ virgindade $)\}$ Nunca mais voltarei a ti, nunca mais voltarei. (fr.104L-P)

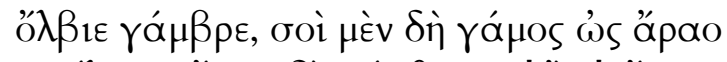

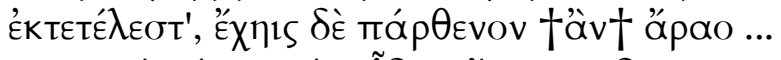

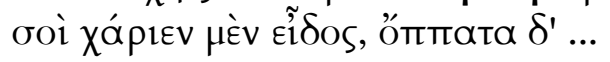

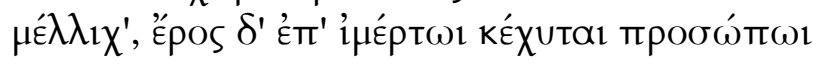


Feliz esposo, tua boda foi realizada conforme desejavas,

Possuis a virgem que desejavas,

Tua figura é graciosa e os olhos da tua noiva são

Doces como mel, a paixão espalha-se desejável no seu rosto.

Afrodite honrou-te por acima de todos. (fr. 112L-P)

Loraux lembra que o casamento era "critério de maturidade" (1993, p.80). É preciso ressaltar que esse evento insere-se dentro da categoria antropológica dos rites de passage, portanto não é raro ser tratado como um delicado limiar delimitado pelo nómos, ou, segundo Calame (1997, p.11),

Consecrating a particular moment in the physiological cycle of life peculiar to the individual, such as the menarche for young girls, the rite of puberty has a different and more private character than tribal initiation; the differences have often not been distinguished with sufficient rigor.

O tratado médico em questão aborda justamente a ultrapassagem desse limite estabelecido para o amadurecimento da mulher. Dessa forma, o médico trata a $\mu \alpha v i ́ a$

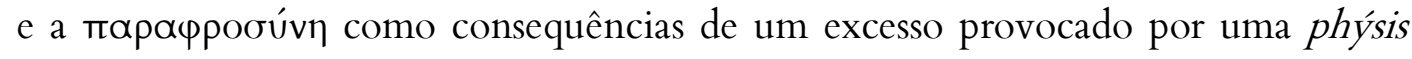
que não se submete ao nómos, como um castigo, não divino, mas certamente impelido pelo desrespeito ao limite imposto por aquele nómos basiléus pánton.

\section{Texto grego e tradução}

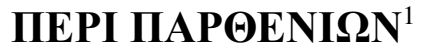

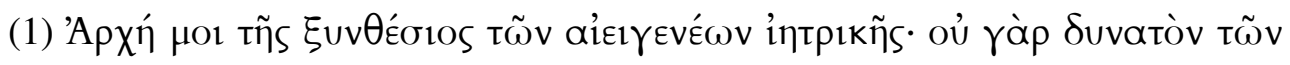

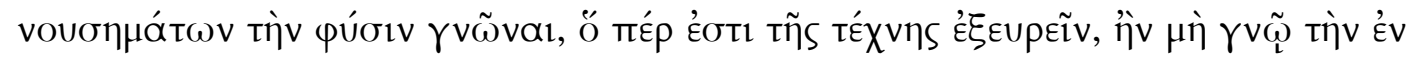

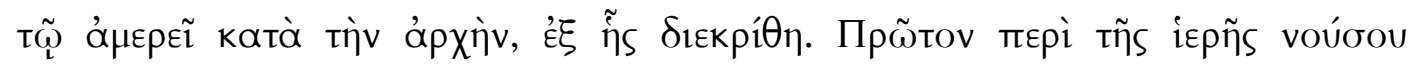

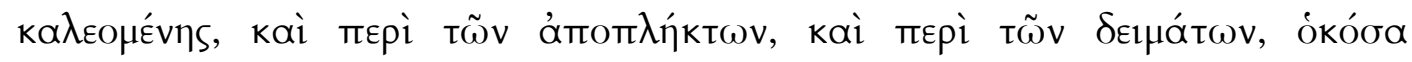




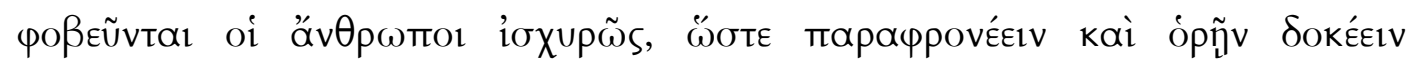

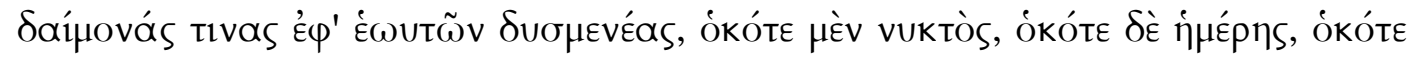

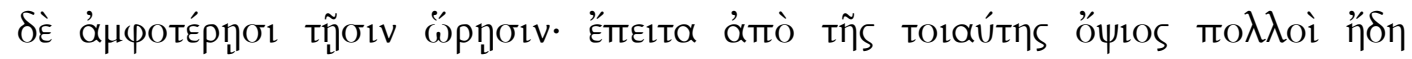

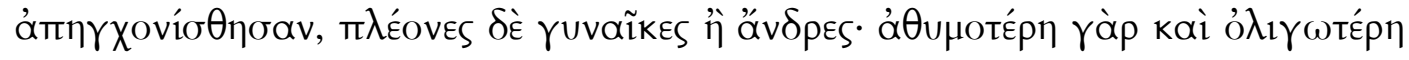

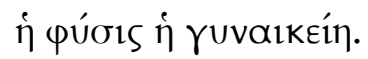

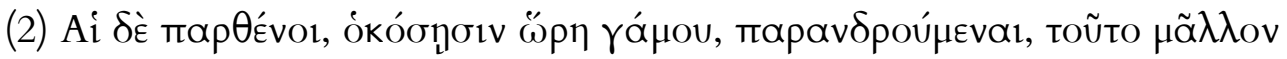

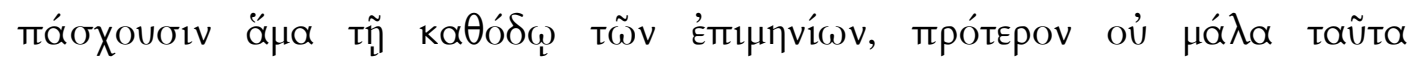

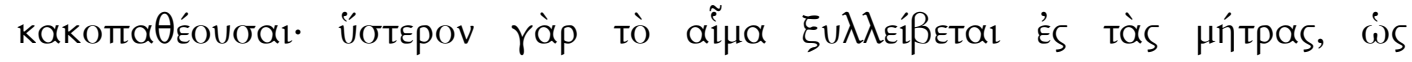

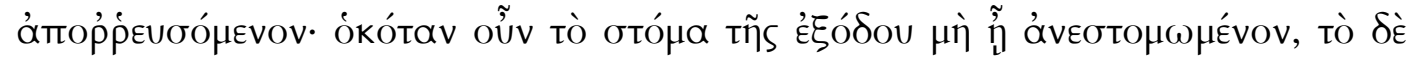

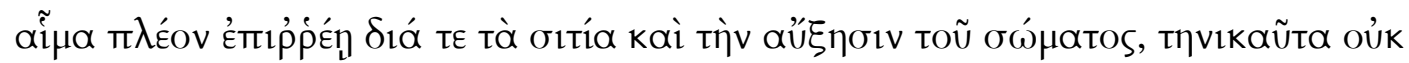

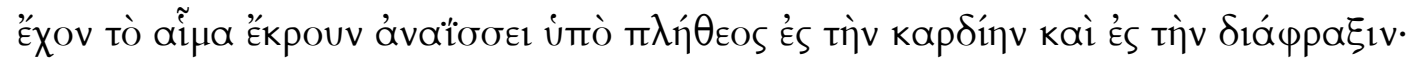

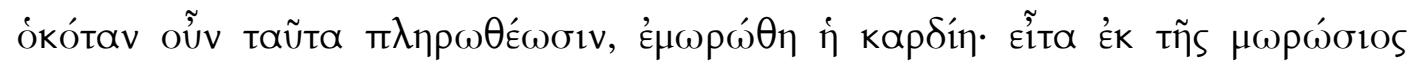

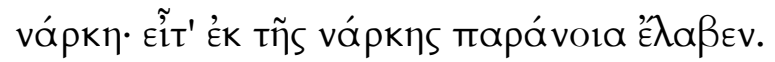

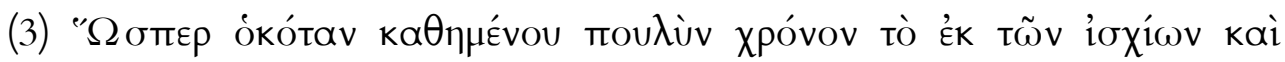

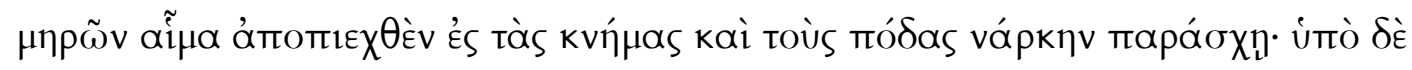

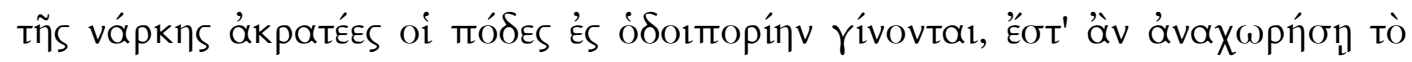

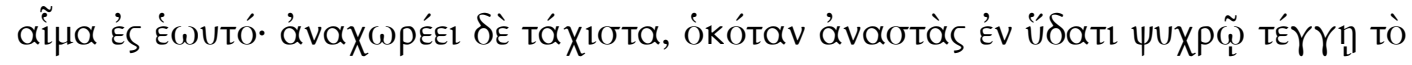

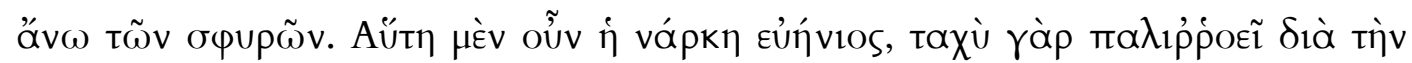

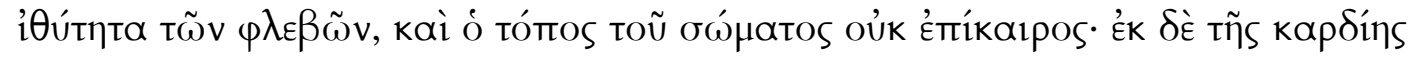

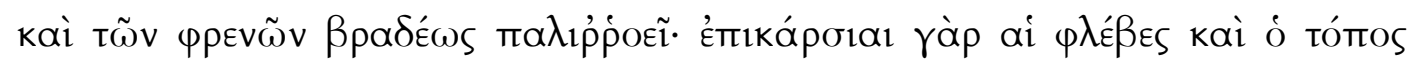

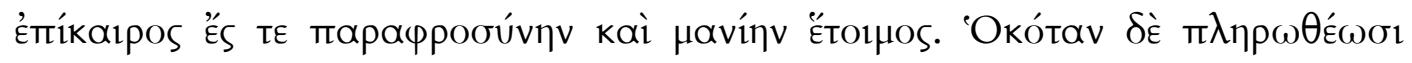

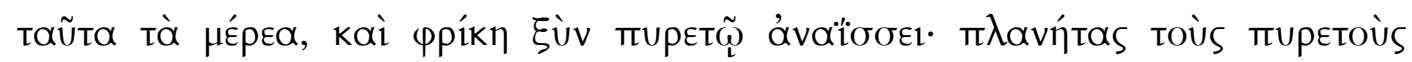

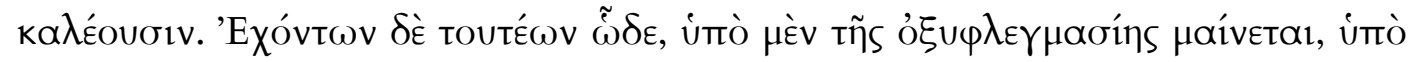

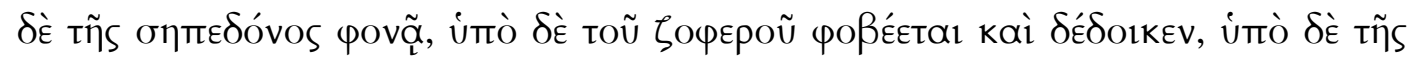

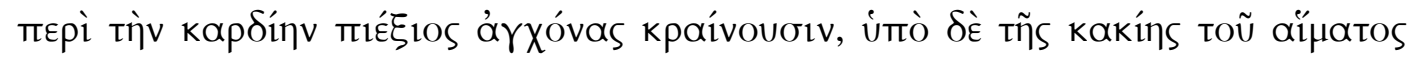

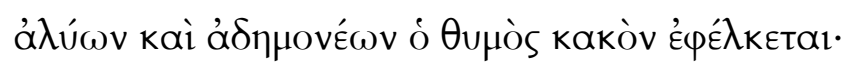

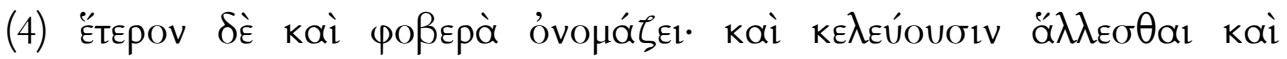

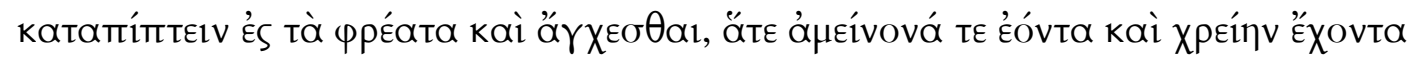

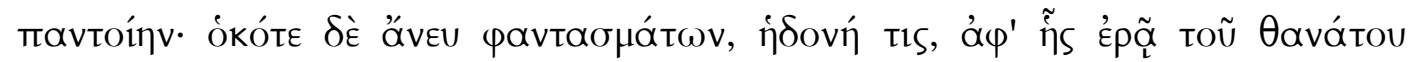

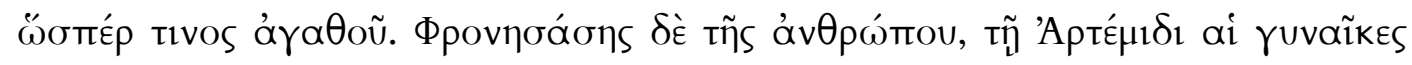

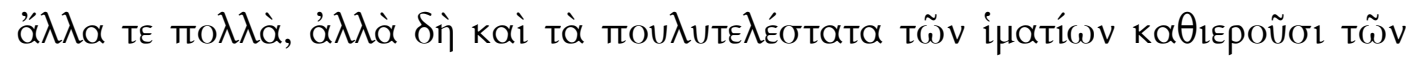




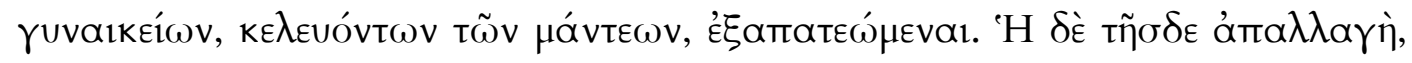

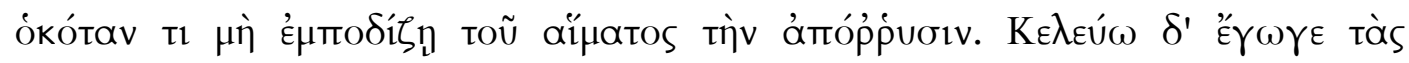

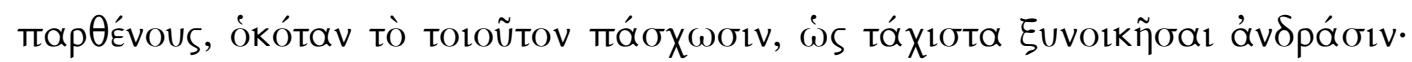

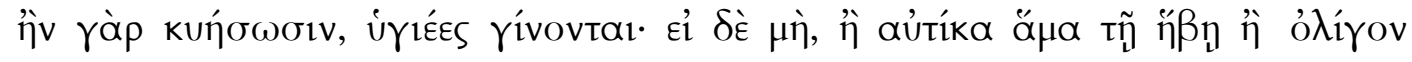

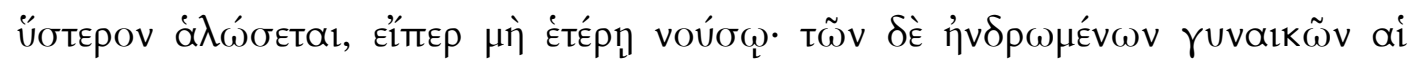

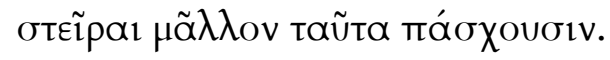

\section{Da doença das virgens}

(1) O princípio da composição da medicina é o mesmo das coisas eternas²: não se pode conhecer a natureza das doenças, o que é a procura da $\tau \dot{\chi} \chi \vee \eta^{3}$, se não se a conhece através do seu princípio, a partir do qual a julga ${ }^{4}$ Em primeiro lugar, a respeito da doença chamada sagrada ${ }^{5}$, e a respeito daqueles que sofrem ataques, e do medo que atemoriza fortemente os homens, de forma a fazê-los delirar e acreditar ver numes hostis a eles tanto durante o dia, quanto durante a noite e em ambos os momentos: assim, muitos se estrangulam imediatamente por causa desta visão, mais

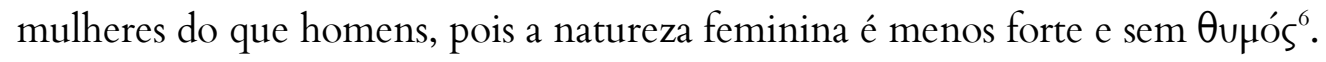

(2) As virgens para as quais chega a hora do casamento, permanecendo solteiras, sofrem mais na ocasião do período mensal, embora antes não padeçam tanto esses males, porém mais tarde, o sangue se acumula no útero para que escorra. Então, não estando o orifício de saída suficientemente aberto, a maior parte do sangue corre por causa da alimentação e do crescimento do corpo, porém não tendo o sangue escorrido, sobe, devido à abundância, em direção ao coração e ao diafragma ${ }^{7}$; quando esses enchem, o coração enlouquece, seja por causa da loucura, o intumescimento toma, seja por causa do intumescimento, a demência.

(3) Quando permanece parado por muito tempo, o sangue dos quadris e das coxas, pressionado em direção aos tornozelos e aos pés, causa intumescimento; por

causa desse intumescimento, os pés tornam-se fracos para caminhar; se parar, o sangue retorna a si mesmo, mas cede rapidamente quando levantada e molhada em água gelada a parte de cima dos tornozelos. Esse intumescimento é suportável, já que (o sangue) flui de volta rapidamente por causa do dilatamento das veias, e sua 
posição no corpo não é duradoura, mas volta a fluir lentamente a partir do coração e do diafragma, pois as veias (ali) são oblíquas e o lugar de permanência é propício ao delírio e à loucura ${ }^{8}$. Quando essas partes enchem, a febre acompanhada de calafrios se eleva: chamam estas febres de errantes. Sendo assim, sob a ação da oxifleumasia ${ }^{9}$, enlouquece; sob a ação de infecção purulenta, mata-se; quando na escuridão, amedronta-se; pela pressão em torno do coração, estrangula-se; sob a ação do mal do sangue, o Өupós, agitado e angustiado, carrega este mal penosamente.

(4) Outra maneira de chamá-las é de terríveis; e ordenam lançar-se nos poços, como se isso fosse o melhor e o mais útil de todas as coisas; quando, sem visões, há um prazer a partir do qual se ama a morte como se fosse uma coisa boa. Ao estarem conscientes, muito frequentemente, as mulheres, ordenadas pelos oráculos, dedicam a Ártemis os mais luxuosos dos vestidos do gineceu, mas se enganam. A sua cura acontece quando não se impede o fluxo de sangue. Ordeno, por minha parte, às virgens que padecem tal mal, a se casarem o mais rápido possível com homens; pois ao engravidar, tornam-se sãs. ${ }^{10}$ Caso contrário, durante a adolescência ou pouco depois, serão tomadas por essa ou por outra doença. Dentre as mulheres casadas, as estéreis padecem esses males.

\section{NOTAS}

\footnotetext{
${ }^{1}$ A tradução aqui apresentada baseou-se no texto estabelecido por Émile Littré.

${ }^{2}$ Trata-se do termo aỉı $ү \varepsilon v \varepsilon ́ \omega v$, que optamos por traduzir por "das coisas eternas". García Gual (1988, p.327), embora também o traduza assim, assinala em rodapé que uma outra opção possível para esse termo seria "divino", se se levasse em consideração a possível relação com o tratado Da doença sagrada.

${ }^{3}$ E possível reconhecer uma postura análoga a esta no tratado Da dieta: "Afirmo que para compor um escrito acertadamente sobre a dieta, é preciso antes que nada conhecer e discernir a natureza do homem por inteiro: conhecer a composição de cada parte desde o princípio, discernir por quais partes está governado; porque se não se conhecer a composição elementar, será impossível saber o que vem a ser a partir deles." (Da dieta, 1,1)

${ }^{4}$ A consciência do médico é o grande diferencial entre o iatrós e o idiótes, e é essa mesma consciência a delimitadora e configuradora do campo de prática e de conhecimento da medicina hipocrática e do lugar social do médico.

${ }^{5}$ Sobre doença sagrada e a relação da medicina com o divino, ver Cairus, 1999 e Cairus e Ribeiro Jr., 2005.

${ }^{6}$ Sobre o thymós, v. Cairus, 2006.

${ }^{7}$ Uma das diferenças principais entre o Da doença sagrada e o Das virgens diz respeito à sede do corpo. Neste tratado, localiza-se no coração e diafragma e no outro, na cabeça.
} 
${ }^{8}$ Mavía é o termo geral para a loucura. É um estado que pode ter várias causas. Naturalmente os hipocráticos procuram causas fisiológicas para ela. Platão, no Fedro (265a), fala da $\mu$ avía dos poetas, que "enlouquecem" pelo seu enthousiasmos e salienta duas formas: "a que se deve às doenças dos

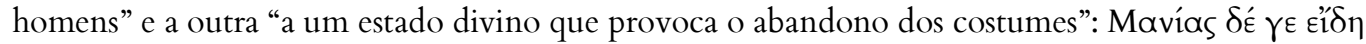

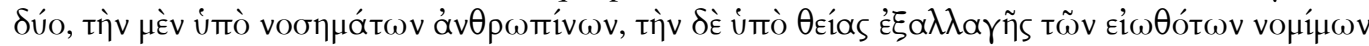

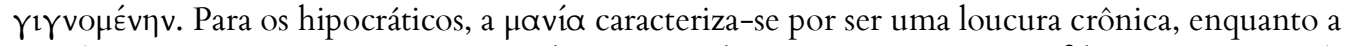

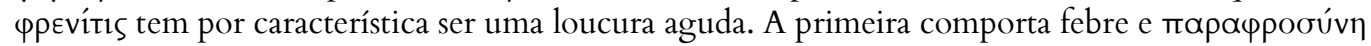

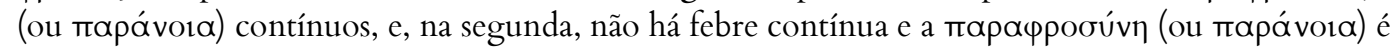

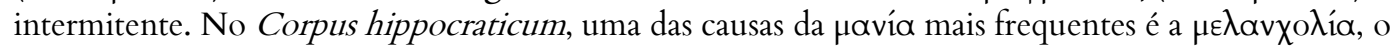
excesso de bile negra. No caso do tratado Das virgens, a causa, claro, não é a bile negra, mas o excesso de sangue.

${ }^{9}$ inflamação aguda

${ }^{10}$ Nota-se, neste trecho, a reconhecida fragilidade da argumentação acerca do diagnóstico e da etiologia da manía. Pode-se mesmo entrever, a partir desta fresta, a posição moral e, por conseguinte, ética do médico tratadista. Para Garcia Gual, "no que diz respeito às terapias e à frequente recomendação do ato sexual, não pode se ver novamente o médico-macho com sua terapia fálica. Os pessários uterinos não são uma vera e propria terapia fallica, mas um remédio de uso tópico”. (1988, p.29) [tradução minha]pessários uterinos não são uma vera e propria terapia fallica, mas um remédio de uso tópico". (1988, p.29) [tradução minha]

\section{BIBLIOGRAFIA}

ARISTÓTELES. Problema XXX, 1: O homem de gênio e a melancolia. Introdução, tradução e notas de Jackie PIGEAUD. Rio de Janeiro: Lacerda, 1998.

BACELAR, Agatha P. A liminaridade trágica em Ájax, de Sófocles. Rio de Janeiro: UFRJ, Faculdade de Letras, 2004. Dissertação de Mestrado em Letras Clássicas.

CAIRUS, Henrique F. Os limites do sagrado na nosologia hipocrática. Rio de Janeiro: UFRJ, Faculdade de Letras, 1999. Tese de Doutorado em Letras Clássicas (Língua e Literatura Grega).

- A alma do corpo e o corpo da alma entre os gregos antigos. In: Calíope - presença clássica, n.15, Rio de Janeiro, dez./2006.

CAIRUS, Henrique F. \& RIBEIRO JR., Wilson A. Ars Longa: O doente, o médico e a doença na Grécia Antiga. Rio de Janeiro: Ed. Fiocruz, 2005.

CALAME, Claude. Choruses of young women in Ancient Greece. London: Rowman \& Littlefield, 1997.

HIPPOCRATE. Du régime. Texte établi et traduit par Robert JOLY. Paris: Les Belles Lettres, 1967. 
HIPPOCRATES. With an english translation by W.H.S. JONES and E.T. WITHINGTON. London/Cambridge: Loeb Classical Library, 1923-92.

JOLY, Robert. Le niveau de la science hippocratique. Paris: Les Belles Lettres, 1966.

JOUANNA, Jacques. Hippocrate. Paris: Fayard, 1992.

KING, Helen. The disease of virgins. New York : Routledge, 2004. . Hippocrates' Woman: Reading the female body in ancient Greece. New York: Routledge, 1998

LORAUX, Nicole. Maneiras trágicas de matar uma mulher: imaginário da Grécia Antiga. Rio de Janeiro : Jorge Zahar, 1993.

OEUVRES complètes d'Hippocrate. Traduction et notes philologiques par Émile LITTRÉ. Paris, Academie Royale de Médecine, tomo I, 1839; tomo II, 1844; tomo IV, 1849 ; tomo VII, 1851 ; tomo VIII, 1853 ; tomo IX, 1861a; tomo X, $1861 \mathrm{~b}$.

PADILLA, Mark W. (Ed.). Rites of Passage in Ancient Greece: Literature, Religion, Society. London / Ontario: Associated University Press, 1999.

PIGEAUD, Jackie. Folie et cures de la folie chez les médecins de l'antiquité grécoromaine. Paris: Les Belles Lettres, 1987.

TRATADOS hipocráticos. Tradução, introduções e notas por Carlos GARCÍA GUAL (org.), Maria D. NAVA, J. LÓPEZ FÉREZ, B. ÁLVARES CABELLOS et alii. Madrid: Gredos, 1983-1990. 6 vols.

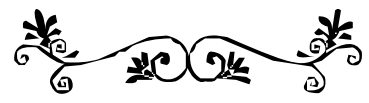

